\title{
Identidade: singularidade: conceitos presentes na arte
}

Paula Ávila Kepler*

RESUMO: O artista com enfoque político, em sua crítica, precisa cada vez mais recorrer ao conhecimento transdisciplinar da produção do sujeito no meio cultural e socioambiental. Os conceitos de identidade e singularidade envolvem nuances e complexidades. Não poderia simplesmente contrapor identidade à diferença, como dois polos opostos e excludentes, quando as inter-relações são menos dicotômicas ou homogêneas, mesmo porque a realidade não o é. Trata-se de um debate relacionado às formas de pensar a construção de um sujeito. $\mathrm{O}$ artigo levanta questões fora do campo institucionalizado da tradição artística, gerando uma reflexão sobre as diferenças, quase labirínticas, presentes na arte conceitual.

PALAVRAS CHAVES: Identidade, singularidade, arte.

ABSTRACT: The artist with political focus, in his criticism, must increasingly resort to the transdisciplinary knowledge of the subject production in his socio-cultural environment. Identity and singularity concepts encompass nuances and complexities. It is not possible to simply oppose identity and difference as two opposite and mutually exclusive poles, the interrelationships are less dichotomous or homogeneous, specially because reality is not. It is a debate related to the thinking ways of the subject construction. The article raises issues outside the institutionalized field of artistic tradition, and generates a reflection on the differences, almost labyrinthine, that are present in the conceptual art.

KEYWORD: identity, singularity, art.

*Paula Ávila Kepler é Mestre em Artes pela Universidade do Estado do Rio de Janeiro 
Os pesquisadores da década de 1960 costumam dizer que o artista conceitual deixou o ateliê para vivenciar diretamente as mudanças sociais e as emergências a seu redor. O desafio passou a ser imergir na matéria múltipla de seu tempo, sem preconceitos ou métodos fixos, de modo desprendido. Repenso se essa atitude comum aos artistas da época seria mesmo consciente, diante das mudanças causadas pelas grandes transformações do período, como a globalização do capitalismo e das lutas. Como o artista poderia ficar estático diante da desestruturação do sujeito e dos paradigmas institucionais antes vigentes, bem como, diante da descentralização de lugar, tornado mais fluido, aberto e multidimensional. Depois da década de 1960, o investimento subjetivo do artista na arte acaba se inscrevendo noutro panorama produtivo. Muitas vezes, uma produtividade não palpável, sem produzir diretamente coisas e objetos, passando a concentrar-se nos processos e nos signos, no deslocamento constante, no transitório, nos empuxos e intensidades desapegadas das instituições e modelos da arte representativa e do museu tradicional.

As mudanças do mundo dos artistas e da arte acompanharam e se colocaram em relação às transformações de seu tempo. O artista não estabelece dogmas ou critérios dados pela organização social e política. Assume um imperativo subversivo de contrapor-se e reinventar-se ante as problemáticas, que o permite explorar novos campos. Com essa qualificação, o artista não se isola do mundo, sequer no momento da produção ou performance. Pelo contrário, as ocorrências ambientais, sociais e sensíveis o afetam e ele põe em jogo com o ambiente. Há um jogo constante de afinidades disparadas por seu trabalho e colhidas em estado bruto em espaços até então desqualificados para o fazer da arte. As mudanças da subjetividade através dos anos 1960 impactam o mundo dos artistas, abalando as identidades mais tradicionais do que era arte, o seu lugar, seu território, sobre como se produzir artisticamente e o próprio artista como agente de seu tempo.

O pesquisador em cultura Stuart Hall oferece um quadro de análise para as dinâmicas de constituição e dissolução das identidades. Seu campo de estudo é o cenário histórico e político de transição, que os anos 1960 marcariam. Trata-se da transição entre o período moderno propriamente dito para um campo ambivalente, bifurcado no plano da análise em dois componentes: a) a modernidade tardia; b) a pós-modernidade. A primeira implicaria o desenvolvimento de virtualidades já contidas na modernidade, enquanto a última, hipótese que o autor adota, assume a situação de ruptura irremediável com a modernidade. O sociólogo procura diagnosticar e entender as demandas do sujeito contemporâneo. A marca dos novos tempos 
é a instabilidade, o descentramento, a falta de um terreno firme para ancorar as crenças, práticas, ideologias e discursos normativos. Ficam assim instáveis as identidades sociais e culturais, que na modernidade estariam bem instaladas em um paradigma mais coeso. $O$ sujeito aos poucos se dissolve, dando lugar ao jogo entre subjetividades, à efemeridade e à incerteza. Para o pesquisador, a identidade numa concepção moderna, era o elo entre o sujeito e os mundos culturais, responsável por "assegurar nossa conformidade subjetiva com as necessidades objetivas da cultura" (HALL, 2005, p.12). Essa segurança entre o sujeito e sua cultura se perde na transição para a pós-modernidade.

A identidade, segundo Stuart Hall, estabiliza o sujeito em seu território, conferindo-lhe pontos de apoio e de justificação claros e seguros. Com a passagem para a pós-modernidade, esses pontos são impactados por novas dinâmicas de relação, que perturbam, desestabilizam e embaralham as referências da realidade social e do mundo cultural. A nova sensibilidade pós-moderna condiciona o acesso a outros modos culturais e comportamentais e é nesse terreno que se dá a quebra de paradigma. Por mais que a pessoa tente se manter atrelada ao paradigma anterior, mais tradicional quanto às identidades, a própria dinâmica social, o modo de produção, a forma de transitar pela metrópole e pelo mundo acabam exigindo a readaptação dos sujeitos. O contato com uma cultura diferente pode ser ocasionado de modo voluntário ou não, através do trânsito de pessoas em função da economia, do acesso aos espaços virtuais, das enormes migrações e ocupações territoriais, entre outros fenômenos. Imerso numa mídia e entretenimento globalizados, entre os fluxos intensificados de comunicações e transportes, o sujeito pressente as mudanças geradas pela globalização e pelos avanços tecnológicos. As identidades tradicionais das mais diferentes culturas são deslocalizadas com uma pluralidade nada homogênea, bastante polivante e mesmo conflitiva, de novas experiências e modos de estar-no-mundo. Segundo o autor, os múltiplos encontros, bons ou não, de hibridação ou de dominação, entre as identidades culturais é que vai gerar a crise da identidade. Essa crise tem início quando "algo que se supõe como fixo, coerente e estável é deslocado pela experiência da dúvida e da incerteza" (HALL, 2005, p.9), como cita Kobena Mercer. Anthony Giddens sintetiza a grande transformação:

"na medida em que áreas diferentes do globo são postas em interconexão umas com as outras, ondas de transformação social atingem virtualmente toda a superfície da terra - e a natureza das instituições modernas." (HALL, 2005, p.15) 
A subjetividade na pós-modernidade resulta desse colapso do que antes era certo e firme, e navega num oceano de potências fragmentadas, de destroços das certezas e ideologias, cedendo lugar para o jogo das diferenças, a multiplicidade, a decomposição e recomposição de agregados culturais e sociais, o que não deixa de produzir híbridos, pastiches, mosaicos e monstros. Vale anotar, de passagem, que essa percepção considerada pós-moderna já existe, embrionariamente, no conceito de antropofagia de Oswald de Andrade, quando o modernista brasileiro fala, por exemplo, no Manifesto Pau Brasil sobre a "contribuição milionária de todos os erros". Como falamos. Como somos" (ANDRADE, 2011, p.17). As escolhas comportamentais tornam-se flexíveis, na mesma medida em que se flexibilizam o mundo do trabalho, a produção fabril, as relações interpessoais e as próprias instituições do direito e da cultura. É um período de sucessivas desregulamentações, onde a fluidez e maleabilidade se tornam elas mesmas componentes das forças produtivas do homem. As identidades tradicionais, antes claramente identificáveis e dizíveis, como os conceitos clássicos de classe, gênero, sexualidade, etnia, raça e nacionalidade, explodem em linhas de força, numa multiestratificação de camadas que se interpenetram e se organizam mutuamente. Dois autores que exprimem bem, por assim dizer, essa reorganização geral dos signos, além da dicotomia moderna entre significado e significante, foram os filósofos Gilles Deleuze e Félix Guatarri, que escrevem em Mil Platôs:

Quanto à linguagem, não sabemos muito bem o que fazer com ela: o grande Déspota tinha decidido que seria preciso conferir a ela um lugar à parte como bem comum da nação e veículo de informação. Desconsideramos assim quer a natureza da linguagem, que só existe em regimes heterogêneos de signos, que distribuem ordens contraditórias em vez de fazer circular uma informação, quer a natureza dos signos que exprimem precisamente as organizações de poder ou os agenciamentos e nada têm a ver com a ideologia como suposta expressão de um conteúdo (a ideologia é o conceito mais execrável que esconde todas as máquinas sociais efetivas). (DELEUZE; GUATARRI, 1995, p.84)

A grande transformação também incide sobre as lutas políticas e os movimentos sociais, que os anos 1960 foram pródigos. Da ação global contra a Guerra do Vietnã às lutas anticoloniais da África, à Revolução Cultural de Mao (revolução dentro da revolução), passando pelas guerrilhas sul-americanas, o movimento por direitos civis nos Estados Unidos e as mobilizações de operários, estudantes e agentes culturais em toda a Europa (a Primavera de Praga, o Maio de 1968 na França, o Outono Quente de 1969 na Itália, a efervescência político-cultural na Holanda e Alemanha etc). Foi um tempo de radicalidade escancarada, com a formação de 
novas organizações e discursos políticos, vanguardas, movimentos sociais e lutas globais. Boa parte dessas revoltas está atrelada à luta contra a opressão operada por meio das identidades. A identidade como prisão imposta ao colonizado, ao negro, ao indígena, à mulher, ao jovem, ao homossexual, em todo caso como peça das engrenagens de funcionamento das normas sociais e culturais, que conservavam uma ordem desigual, injusta e violentamente repressora. Os movimentos das minorias reforçam a contestação às identidades fixadas pelos poderes dominantes, desestabilizando a linguagem, os códigos, os signos, a disciplina dos corpos, espaços e tempos, que caracterizam o paradigma da modernidade.

Nesse sentido, o campo da arte é inundado por propostas e tarefas relacionadas à reinvenção das identidades, à irrupção de sentidos e significados contra a ordem identitária vigente. 0 engajamento artístico, agora, tende a deslizar e se contrapor às identidades tipicamente modernas: a nação, o estado, o povo, a classe, o cidadão. Contestam-se essas identidades que constroem a norma do homem branco ocidental trabalhador e cidadão, contra a miríade de sujeitos sociais oprimidos com uma condição social e cultural inferiorizada, explorada e moralizada. Não se pode contornar como todas essas lutas generosas foram fundamentais para a transição ao paradigma da pós-modernidade, uma conquista de direitos e melhores condições por parte da resistência mais do que mera reestruturação da cultura da produção capitalista, que, de qualquer modo, também acompanha esses processos.

Hoje, vive-se um tempo de múltiplas demandas de minorias, que se sobrepõem e se recombinam continuamente, numa dispersão positiva de pautas e frentes de luta. A política se desenvolve entre o confronto de direitos adquiridos e as múltiplas demandas por novos direitos. Stuart Hall usa o termo "jogo de identidades" (HALL, 2005, p.20), para mostrar o cenário conflituoso do sujeito contemporâneo, sempre inacabado e de limites incertos, atravessado por campos de polarização e descontinuidades. Nessa situação contemporânea, nenhuma identidade individual (o indivíduo mesmo como ente atomizado) seria capaz de alinhar todas as identidades diferentes, elas circulam, erram e se disseminam pela sociedade e um ente individual é incapaz de estabilizá-la ou constituí-la de modo seguro:

\footnotetext{
“Uma vez que a identidade muda de acordo com a forma como o sujeito é interpelado ou representado, a identificação não é automática, mas pode ser ganha ou perdida. Ela tornou-se politizada. Esse processo é, às vezes, descrito como constituindo uma mudança de uma política de identidade (de classe) para uma política de diferença. "(HALL, 2005, p.21)
} 


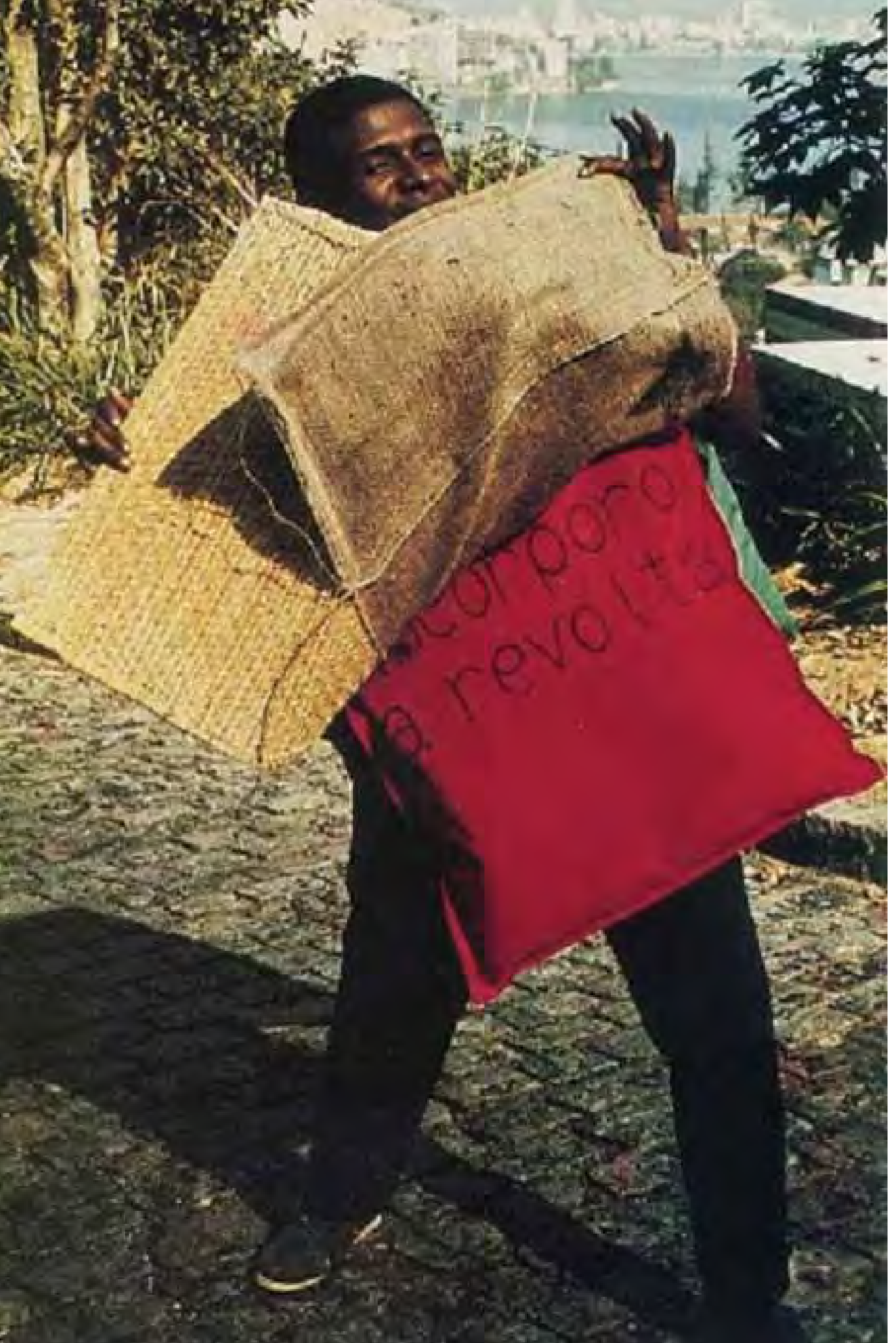

Hélio Oiticica

Nildo da Mangueira veste o Parangolé P15,

"Incorporo a revolta", capa 11, 1967.

Fonte: Projeto HO: Catalogue Raisonné. Ref: 2407.89-p2 
Um autor que desenvolve muitas temáticas, em diversos campos do conhecimento, pensando a identidade e a diferença é o filósofo francês Michel Foucault. É um dos considerados pós-estruturalistas da história da filosofia francesa, que apareceram no cenário acadêmico em contraponto aos estruturalistas como o antropólogo Claude Lévi-Strauss e o linguista Ferdinand Saussure. Ele é também classificado como um pensador da descontinuidade, mais preocupado com os momentos das rupturas, as passagens de sistemas históricos de pensamento e as incoerências internas às ciências humanas e os dispositivos de poder. Assim, pode-nos ajudar a aprofundar o estudo tomando por foco a transição histórica entre a modernidade e a pós-modernidade.

Para Michel Foucault, não importa tanto a identidade em si, como se fosse uma substância permanente. O que importa são os processos de subjetivação e os mecanismos de identificação que fazem parte de um determinado dispositivo de poder. O filósofo se refere à construção da identidade e não meramente à identidade como algo dado, definitivo ou fechado. $O$ fechamento da identidade sobre alguém obriga essa pessoa a comportamentos, expectativas e, auto cobranças específicos: "trata-se de compreender por meio de quais mecanismos epistemológicos essa identidade pode ser fixada, organizada, hierarquizada, controlada". (REVEL, 2011, p.38). Dessa maneira, as ciências humanas operam como formas de poder ao objetivar uma identidade a partir dos sujeitos sociais. Existe uma produção de objetos-identidades com a finalidade de obrigar e aprisionar as pessoas. O próprio indivíduo já é um resultado das múltiplas identificações que ele sofre e a partir do que se relaciona consigo mesmo e com os outros, resistindo ou não. Por conseguinte, Foucault entende que receber uma identidade e ser identificado traz uma dupla captura: como objeto do discurso e, simultaneamente, objeto de práticas. Nessa linha de pensamento, a identidade é colocada por Foucault como um efeito de poder exercido sobre as pessoas.

Numa fase posterior da obra de Foucault, contudo, a identidade também foi analisada por outra perspectiva, como resistência. Mesmo porque, dentro da analítica do filósofo em questão, se existe a aplicação de um poder, ele pode ser produtivo também no sentido de resistência e reinvenção. Como explica a comentadora Judith Revel: “Ele será levado a formular uma crítica radical das identidades e a desenvolver, ao contrário (...), a definir uma prática política, subjetiva e coletiva, porém não identitária", (REVEL, 2011, p.82). É outra fase na qual ele percebe como o jogo das identidades (como crítica) não deve ser abandonado para movimentos de afirmação de minorias, como as de gays, lésbicas, bissexuais e transexuais (LGBT). Nesse 
momento, Judith Revel constata a admissão por parte de Foucault de uma "espécie de EU fervilhante, de disseminação identitária, de afirmação radical da 'diferença intensiva' e de resistência à identificação, essa pesquisa é transformada a partir de sua reformulação política dos anos 1970",(REVEL, 2011, p.82). A seguir, é citada passagem relevante do pensamento de Michel Foucault sobre a identidade quanto à sua utilização política nos grupos ativistas (como os queers):

Ainda que, do ponto de vista tático seja importante dizer Eu sou homossexual, em minha opinião, não é mais preciso, a longo prazo e no âmbito de uma estratégia mais ampla, indagar a identidade sexual. Não se trata, portanto, nessa circunstância, de confirmar sua identidade sexual, mas de recusar a injunção de identificação da sexualidade, das diferentes formas de subjetividade. (REVEL, 2011, p.83)

Nesse desenvolvimento teórico, decorrente do próprio movimento do pensamento e da militância do filósofo ao longo dos anos, aparece outra acepção de identidade. Não fica evidente só a identidade como objeto dos discursos e práticas, determinado pelos poderes e sua inscrição nos corpos das pessoas e das populações. Evidencia-se, também, a possibilidade de fugir desses aparelhos de poder para construir uma identidade outra, num outro sentido possível de liberdade e de modo de vida. Nessa outra face da "identidade", que tem repercussões na arte e na política, o termo mais preciso não é mais identidade, mas subjetivação e subjetividade.

O conceito de subjetividade (REVEL, 2011, p.146), aparece em filósofos pós-estruturalistas como Foucault para se distinguir do conceito de sujeito. O sujeito era tradicionalmente entendido como um ente coeso que subsiste em si seja como uma consciência individual ou agregação coletiva identificada em si mesma. O sujeito é idêntico a si mesmo e permanece nessa situação, o que pode conferir segurança aos membros que se identificam com ele. Para Michel Foucault, no entanto, o sujeito é uma atividade constante de construção, que não tem como ser interrompida. Todo sujeito tem uma história, uma genealogia de relações de poder e saber lançadas sobre ele, que o constituem. A subjetividade surge quando se considera o lado do processo, em vez dos produtos (as identidades), isto é, o em movimento, o inacabado, os pontos de resistência e também os acasos. Foucault esclarece que o problema da subjetividade é "a maneira como o sujeito realiza a experiência de si mesmo num jogo de verdade, no qual ele se relaciona consigo", (REVEL, 2011, p.147). 
Por "técnicas de si" (REVEL, 2011, p. 147-148), trata-se de um campo de estudos do filósofo francês na sua fase final, já na década de 1980. A produção de subjetividade depende de uma relação com o si mesmo, de cuidado de si. Isto significa, em vez de classificar e listar elementos definidos de identidade, buscar compreender como os sujeitos elaboram o próprio desejo em um determinado modus vivendi, em certo feixe histórico de relações possíveis. Desta maneira, torna-se possível inscrever-se em determinados jogos de verdade, que estabelecem as regras onde se podem combinar elementos para constituir as identidades. Estas existem num processo de subjetivação que depende dessa matriz produtiva, o que pode ser chamado de "produção de subjetividade." Mais uma vez, vale a explicação de Revel:

O problema parece ser, para Foucault, investigar os jogos de verdade, isto é, as relações por meio das quais o ser humano se constitui historicamente como experiência, que possibilitam ao homem uma auto avaliação quando este se identifica como louco, doente, desviado, como trabalhador, ser vivente ou falante, ou ainda como homem de desejo. (REVEL, 2011, p.149)

Adentrando o tema conceitual da "produção de subjetividade", pode-se passar ao trabalho rico desenvolvido em coautoria pelos psicanalistas Félix Guattari e Suely Rolnik. Eles também partem do conceito de subjetividade, que assume uma "natureza industrial, maquínica, ou seja, essencialmente fabricada, modelada, recebida, consumida." (GUATTARI; ROLNIK, 2010, p.33). As subjetividades são produzidas por máquinas sociais. Máquinas, nesta acepção, não devem ser entendidas por mecanismos determinísticos, como um mecanicismo, mas por um conjunto de peças e acoplamentos que se relacionam de modo contingente, frequentemente por acaso e sem uma racionalidade previsível. A produção de subjetividade, para os autores, se distancia de concepções teóricas de ideologia, de uma superestrutura determinada por relações mais substantivas (de produção), isto é, numa estrutura determinista. Eles consideram essas concepções "dogmáticas" e "as mutações de subjetividade não operam no registro das ideologias, mas no próprio coração dos indivíduos, em sua maneira de perceber o mundo, de se articular com o tecido urbano, com os processos maquínicos do trabalho" (GUATTARI; ROLNIK, 2010, p.34).

O foco dos autores está em pensar os movimentos das minorias, além das identidades que são coladas nos sujeitos sociais, cegando o campo de visão a esses movimentos minoritários. As identidades que nos chegam estão conectadas diretamente às máquinas sociais que são movidas pelas forças. Essas máquinas definem a forma de percepção do mundo, bem como 
os modos de trabalho, organização social, horizonte político e controle social. Está em questão um sistema completo de constituição do mundo, que põe elementos para as pessoas se situarem, identificarem e viverem seus espaços de liberdade, desejo e produção; "a produção de subjetividade constitui matéria prima de toda e qualquer produção [...]Todos os fenômenos importantes da atualidade envolvem dimensões do desejo e da subjetividade", (GUATTARI; ROLNIK, 2010, p.35). A subjetividade é produtiva, e as lutas ao seu redor são imediatamente lutas pela reapropriação das condições de produção. A produção de subjetividade não está no plano do representativo, mas aquém dele, no plano da micropolítica das relações materiais entre as pessoas.

Os trabalhadores da cultura, quem produz e faz cultura, estão operando no nível da produção de subjetividade, e não simplesmente fabricando ou reproduzindo ideologia, como se fosse um plano de representação a camuflar as relações reais de poder e força. A matéria das subjetividades já é a superfície onde opera o sistema político e cultural, e suas resistências, que nunca é homogênea, neutra ou imparcial. Os autores definem dois planos de análise: macropolítico e micropolítico, e propõem maior atenção ao segundo, geralmente negligenciado nas teorias estruturalistas. Isto não significa abandonar o plano macro: "Qualquer revolução em nível macropolítico concerne também à produção de subjetividade ". (GUATTARI; ROLNIK, 2010, p.38). As disputas no plano micropolítico se dão como disputas entre subjetividades.

O conceito de subjetividade é, a seguir, refinado. Novamente em contraposição ao conceito de sujeito que enuncia, é preciso falar em "agenciamento coletivo de enunciação". Esses agenciamentos produzem uma subjetividade, que não se reduz ao indivíduo nem a uma identidade de grupo. Os agenciamentos operam colocando múltiplos elementos em contato e fazendo-os funcionar como máquina social, no social. O indivíduo é modelado a partir de uma identidade do ego consigo, de uma produção serializada de indivíduos identificados entre si (pela nação, pela cultura enraizada, pela categoria de consumo etc). Já a subjetividade atravessa os indivíduos e grupos, desestabiliza as identidades e monta e funciona as máquinas sociais, que se desdobram em comportamentos, sensibilidades, modos de perceber e de inventar mundos possíveis; "a subjetividade está em circulação nos conjuntos sociais de diferentes tamanhos: ela é essencialmente social, e assumida e vivida por indivíduos em suas existências particulares", (GUATTARI; ROLNIK, 2010, p.42). E também: "o indivíduo está na encruzilhada de múltiplos componentes da subjetividade." Só que o contrário dessa definição não vale. As subjetividades não são resultado dos múltiplos componentes dos indivíduos. É, neste ponto 
do desenvolvimento, que aparece a importância de um novo conceito, o de singularidade, que me pareceu essencial para a compreensão das práticas artísticas como capazes de impactar a economia geral do desejo e da subjetividade, os "agenciamentos de enunciação".

Na realidade, o sistema capitalista está realizado no interior dos regimes de produção de subjetividade, sobre as forças sociais criativas e produtivas. Por um lado, sofistica as formas de controle social e exploração. Por outro, também abre um campo de resistência no próprio plano da produção de subjetividades para "imensas possibilidades de desvio e de reapropriação", (GUATTARI; ROLNIK, 2010, p.53). Em nota separada, fazendo referência à obra de Gilles Deleuze e Félix Guatarri, Suely Rolnik é ainda mais clara:

O reconhecimento da produção de subjetividade como base do sistema capitalista (ou socialista burocrático) deve manter-nos sensíveis aos pontos de ruptura desse dispositivo complexo de produção, pontos nos quais se situariam, segundo eles, muitos dos movimentos da atualidade e, finalmente, o reconhecimento de tais pontos de ruptura como focos de resistência política, de maior importância, já que atacam a lógica do sistema, não como abstração, mas como experiência vivida. (GUATTARI; ROLNIK, 2010, p.54)

Singularidade, ou melhor, processos de singularização ocorrem quando movimentos sociais adotam modos de produção de subjetividade que revolucionam as subjetividades colonizadas pelo capitalismo. É o que os autores chamam de "revolução molecular", a possibilidade de produzir subjetividades com autonomia em relação às máquinas sociais que se engrenam para os fluxos do capitalismo: "chamo de processos de singularização algo que frustra esses mecanismos de interiorização de valores capitalistas", (GUATTARI; ROLNIK, 2010, p.55-56). A singularização depende essencialmente de uma atitude de rejeição das subjetividades capitalistas, que capturam os modos de sentir e perceber. Trata-se de recusar a combinação dos elementos das máquinas sociais de produção capitalista, o que também deve acontecer com a reapropriação dos processos maquínicos, inclusive em nós mesmos, e não com algum maniqueísmo. Daí a importância de afirmar outras formas de subjetividade, mais autênticas e autônomas, em relação ao controle social propagado pelo capitalismo.

As resistências de agora se diferem das articulações políticas da década de 1970, por estarem tratando com outro campo de forças que condicionam e subjetivam o conjunto de relações sociais. Não é o caso de opositores como os Estados autoritários, as organizações militares e grupos armados, que exercem opressão física sobre o homem, quando esses próprios entes já são resultados de relações e mecanismos moleculares e de subjetivação que os 
possibilitam em primeiro lugar. Contudo, a tendência é cada vez mais se desarticular essa forma de poder unitária e superestrutural para prevalecer outra, formada por forças mais disseminadas, fluidificadas e inconscientes, que agem no plano dos afetos e na economia do desejo, que interferem nos processos de produção de subjetividade: "não existe, a meu ver, cultura popular e erudita. Há uma cultura capitalística que permeia todos os campos de expressão semiótica",(GUATTARI; ROLNIK, 2010, p.30). Deste modo, a política, antes compreendida pelo modelo do Estado, do partido e das representações por sindicatos e identidades fechadas, torna-se infiltrada cada vez mais em ações menos totalizantes, num plano que transcende a vida situada, e mais cotidianas, moleculares. Ou seja, uma política econômica e cultural, realizada em várias etapas para desgastar menos a imagem, amparada por diferentes redes de comunicação que se beneficiam do sistema, com o marketing publicitário agindo favorável, desarticulando as redes marginais sem deixar o registro dessas ações autoritárias.

A micropolítica fortalece a articulação e o coletivo garante a potência para o exercício criativo de novos modos de vida. Para Félix Guatarri e Suely Rolnik, o capitalismo de agora, onde a cultura de massa é uma peça chave, encontra resistência nos "processos de singularização" (GUATTARI; ROLNIK, 2010, p.22), que escapam dos aparelhos de captura. Enquanto a cultura de massa conforma o sujeito, manipulando seu pensar e agir, assegurando as conformidades subjetivas com as necessidades objetivas da cultura capitalística, numa máquina social de captura que exclui as potencialidades do desejo, os processos de singularização constroem modos de sensibilidade, relações com o outro, modos de criatividade que produzam subjetividade singular, uma rede intrincada de circuitos e fluxos em vaivém, de retroalimentação e sobrecodificação. Os processos de singularização possuem qualidades e expectativas bem próximas a certos aspectos da arte contemporânea, muito polivalente e impossível de analisar fora da lógica maquínica que a inscreve nos processos sociais em tempos de capitalismo como um modo (histórico) de subjetividade.

A diferença entre identidade e singularidade está no resultado dos encontros entre os indivíduos. Não existe uma fórmula exata, é mais um processo qualitativo do que quantitativo, que depende de como se toma os fluxos e as redes que articulam a subjetividade (capturada ou em fuga). Para facilitar o entendimento das questões futuras, os conceitos se desenvolvem, grosso modo, da seguinte maneira: a identidade é o que se tem em comum, é o ponto em que se cimentam as pessoas como identificação recíproca, refletida. É a identificação com algo dado, pré-existente, o que resta de tudo aquilo que foi anulado para que se possa 
estabelecer uma relação com o outro. Para viver numa comunidade onde o regime está baseado na tradição, é preciso abdicar de outras qualidades e interesses que venham a ser diferentes da identidade em questão, e essa é a força comunitária: ser mais do mesmo e não ainda outra coisa. Entretanto, em alguns casos, recusar e evadir não são uma escolha, envolvem resistências em vários níveis. Então, mesmo nos movimentos de lutas das minorias, é possível encontrar um membro que esteja. Alguém que não se encaixe completamente no modelo tradicional. Por outro lado, o indivíduo pode encontrar em outra comunidade a fuga, apoio e defesa necessários para suas escolhas, valendo lembrar as palavras de Stuart Hall que recorre a Karl Marx para firmar o raciocínio: "as sociedades modernas são, portanto, por definição, sociedades de mudança constante, rápida e permanente", (HALL, 2005, p.14), e se diferem das tradicionais por sua capacidade reflexiva.

Pode-se dizer, portanto, que Suely Rolnik e Félix Guatarri consideram que os processos de singularização são a forma principal de resistência dentro de um paradigma de capitalismo que também opera nas subjetividades. Isto não quer dizer que se esteja de volta ao paradigma da ideologia, onde a resistência poderia acontecer em dois planos: nas forças produtivas da infraestrutura ou nas relações de produção superestruturais, na ideologia. A singularidade emerge nas forças produtivas que já são elas mesmas o campo das subjetividades e da economia geral do desejo. Nesse raciocínio, a resposta à resistência pela subjetividade também ocorre nesse nível micropolítico e pode conduzir a dois processos distintos. Primeiro como "resposta normalizadora". Segundo, por meio de "direcionar a singularidade para a construção de um processo que possa mudar a situação, e talvez não só localmente." Apesar disso, num segundo momento, o sistema capitalista não deixa de tentar recodificar os processos de singularização, fazendo uso da novidade para funcionar ainda mais profundamente, o que os autores chamam de "processo de integração": é que os processos de singularização afetam as máquinas de produção social, trazendo consequências de ordem econômica, cultural, política.

Como consequência, ocorre um jogo entre a produção de subjetividade resistente e sua captura. Os processos de singularização podem acabar revertidos para funcionar dentro do paradigma que estavam tentando impactar. Isso pode acontecer de muitos modos e implica uma preocupação diante dos modos como o sistema capitalista tenta integrar as singularidades. 
